\title{
Neurosurgical checklists: a review
}

\author{
Scott L. Zuckerman, M.D., ${ }^{1}$ Cain S. Green, B.S., ${ }^{2}$ Kevin R. Carr, B.S., ${ }^{3}$ \\ Michael C. Dewan, M.D., ${ }^{1}$ Peter J. Morone, M.D., ${ }^{1}$ ANd J Mocco, M.D., M.S. ${ }^{1}$ \\ ${ }^{1}$ Department of Neurological Surgery, Vanderbilt University School of Medicine; ${ }^{3}$ Vanderbilt University \\ School of Medicine, Nashville; and ${ }^{2}$ College of Medicine, The University of Tennessee Health Science Center, \\ Memphis, Tennessee
}

\begin{abstract}
Morbidity due to avoidable medical errors is a crippling reality intrinsic to health care. In particular, iatrogenic surgical errors lead to significant morbidity, decreased quality of life, and attendant costs. In recent decades there has been an increased focus on health care quality improvement, with a concomitant focus on mitigating avoidable medical errors. The most notable tool developed to this end is the surgical checklist. Checklists have been implemented in various operating rooms internationally, with overwhelmingly positive results. Comparatively, the field of neurosurgery has only minimally addressed the utility of checklists as a health care improvement measure. Literature on the use of checklists in this field has been sparse. Considering the widespread efficacy of this tool in other fields, the authors seek to raise neurosurgical awareness regarding checklists by reviewing the current literature. (http://thejns.org/doi/abs/10.3171/2012.9.FOCUS12257)
\end{abstract}

\section{KEY WoRds • neurosurgery • neurosurgical checklist • complication • preventable error}

I

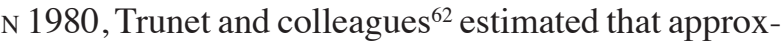
imately $41 \%$ of hospitalized patients were admitted due to iatrogenic disease. Gawande and colleagues ${ }^{29}$ postulated that of all hospital admissions nationally, 3\% resulted in adverse events and $50 \%$ of these events were preventable. In 2000, the Institute of Medicine published To Err is Human: Building a Safer Health System. That publication suggested that there were at least 90,000 deaths annually attributed to avoidable medical errors..$^{5,38}$ Several studies have quantified the summative costs of medical errors. ${ }^{29,58-62,64}$ In Utah alone, a 1999 study estimated that the total cost due to adverse medical events totaled approximately US $\$ 600,000$ for 459 adverse events. ${ }^{60} \mathrm{~A}$ similar study in New York documented mortality rates of $13.6 \%$ and total costs upward of US $\$ 800$ million for adverse events that year.,35 The prevention of these avoidable medical errors has contributed to the

\footnotetext{
Abbreviations used in this paper: DBS = deep brain stimulation; $\mathrm{ICP}=$ intracranial pressure; NASS = North American Spine Society; $\mathrm{OR}=$ operating room; SURPASS $=$ Surgical Patient Safety System .
}

evolving interest in quality improvement measures, with heavy emphasis on surgical checklists.

In 2009, Haynes et al. published the WHO Surgical Safety Checklist. ${ }^{32}$ The 19-item checklist sought to address infection prevention and anesthesia-related complications in surgery. In his 2009 book, Atul Gawande espoused the utility of the WHO checklist in error prevention. ${ }^{28}$ Imported from the field of aviation, his work identifies areas of routine tasks prone to human error and identifies corrective measures to prevent this error. His perspective identifies the intrinsic human fallibility and the inherent inability to provide consistently flawless outcomes with total reliance on individual performance.

Medicine has seen an explosion in checklists aimed at improving patient safety. Whereas general surgery $y^{4,7,9,11}$, $16,18,19,26,48-50$ and anesthesia ${ }^{8,31,42,43,46}$ have published extensively on the use of checklists, neurosurgery has been less productive. Perhaps the product of a smaller field, the need for standardizing preoperative activities is of paramount importance in the high-risk world of neurosurgery. In an effort to advance the use of checklists in neurosurgical 


\section{S. L. Zuckerman et al.}

practice, we provide a summary of previously published neurosurgical operative checklists. It is our hope that this repository of current literature, and the evidence behind it, may expand the use of checklists in neurosurgery.

\section{Methods}

The MEDLINE and PubMed records were searched to identify all published studies pertaining to surgical safety checklists in all surgical fields and in those specific to neurosurgery. The following terms: quality improvement, surgical checklists, preprocedural checklists, vascular neurosurgery checklist, functional neurosurgery checklist, pediatric neurosurgery checklist, oncology neurosurgery checklist, spine surgery checklist, and wrong-site surgery were used as medical subject heading terms and text words. The reference lists of these articles were examined to identify additional relevant research.

\section{Results}

\section{Surgical Checklists}

The presurgical time-out has repeatedly been shown to decrease wrong-site surgery and OR sentinel events and has been endorsed by powerful organizations such as the WHO and the Joint Commission. ${ }^{32,44}$ A landmark study in 2009 by Haynes et al. ${ }^{32}$ introduced the WHO Surgical Safety Checklist to OR staff in 8 international hospitals. Prospective data from 7688 patients showed a decreased rate of death (from $1.5 \%$ to $0.8 \%$ ) and decreased inpatient complications (from 11\% to 7\%) after implementation of the checklist. This study furthered the role of the checklist in modern medicine due to the list's brevity and low cost, as well as its direct link to decreased mortality and morbidity.

The following year, de Vries et al. published the results of their SURPASS checklist, which was also studied using a multicenter, prospective method with 8207 patients. ${ }^{20}$ However, unlike the Haynes checklist, which was limited to the OR, the SURPASS checklist followed general surgery patients from admission to discharge. Decreases in the death rate (from $1.5 \%$ to $0.8 \%$ ) and complication rate (from $27.3 \%$ to $16.7 \%$ ) were noted. Additionally, complication rates for patients with $80 \%$ or more of the checklist completed was significantly lower than for patients with less than $80 \%$ of the checklist completed (7.1\% compared with $18.8 \%$ ). This study demonstrated the efficacy of a checklist devoted to the complete surgical pathway, despite its length and difficulty in implementation.

The checklist is an effective tool in the mitigation of iatrogenic morbidity. Several specialties have made strides with checklists. Table 1 summarizes validated checklists published in other medical and surgical fields and their results.

\section{Neurosurgical Checklists}

In the neurosurgical community, checklists have been evaluated in several areas, including DBS, aneurysm treatment, and spine surgery, as noted in Table $2 .^{13,21,39,44}$,
55,57 To date, no direct link between neurosurgical checklists and patient safety has been published. This lack of evidence provides motivation for the field as a whole to integrate checklists into the standard of care and to prove the worth of these lists, as other fields have.

In making such an effort, neurosurgery can seek to use general surgical checklists, such as the many variations of the nearly ubiquitous time-out, or procedure- and specialty-specific checklists. Neurosurgery is a diverse field with a wide range of procedures, including delicate brain dissection, DBS, complex spinal deformity correction, and endovascular therapies. Each of these subspecialties entails individualized patient and surgical factors that require meticulous attention to detail. In an effort to advance the use of checklists in neurosurgical practice, we provide a summary of previously published checklists applicable to certain neurosurgical procedures in Table 2.

General Neurosurgery. To date, 3 studies have been published detailing surgeons' experience using checklists for general neurosurgical procedures. Da Silva-Freitas et al..$^{14}$ evaluated their modified version of the WHO surgical safety checklist in 44 neurosurgical operations and identified 51 possible sentinel events. Their checklist helped prevent $88 \%$ of possible errors prior to initiation of surgery. Matsumae et al ${ }^{45}$ implemented a similar checklist and used an on-duty safety nurse to ensure that all safety practices were being met.

Lyons $^{44}$ has published perhaps the most robust neurosurgical checklist experience. This author published 8 years of data with an operative checklist, the goal of which was to prevent wrong patient, wrong site, and wrong surgery, summarized in Table 3. Lyons found that in 6313 operative checklists for 6345 patients, compliance was $99.5 \%$. However, he was unable to document a reduction in the number of wrong-site or wrong-patient surgeries due to the infrequency of these incidents. One unique facet of the Lyons checklist was who administered it. Whereas many checklists are completed by OR nurses, the Lyons checklist has a place for the surgeon's signature prior to every case.

Functional Neurosurgery. In recent decades, DBS has developed into a promising approach to medically refractory movement disorders. ${ }^{30,37,65}$ With improved understanding of sensorimotor pathways and psychiatric illness, the indications for DBS have grown. However, as the indications grow, so does the patient population at risk for unfavorable DBS outcomes. The very nature of DBS demands absolute precision with respect to electrode placement. Any operative or perioperative event that could negatively influence electrode positioning imparts a morbidity risk and therefore becomes a potential target for checklist interception. Such events include errors in frame placement, imprecise MRI targeting, improper bur hole location, inaccurate signal recording and electrode implantation, and careless closing. A successful checklist must incorporate boxes for each of these steps if DBS morbidity is to be minimized.

In 2009, Connolly et al. ${ }^{13}$ described the first checklist specifically designed for DBS, which carefully addressed these steps in detail. In 2012, the same group published 


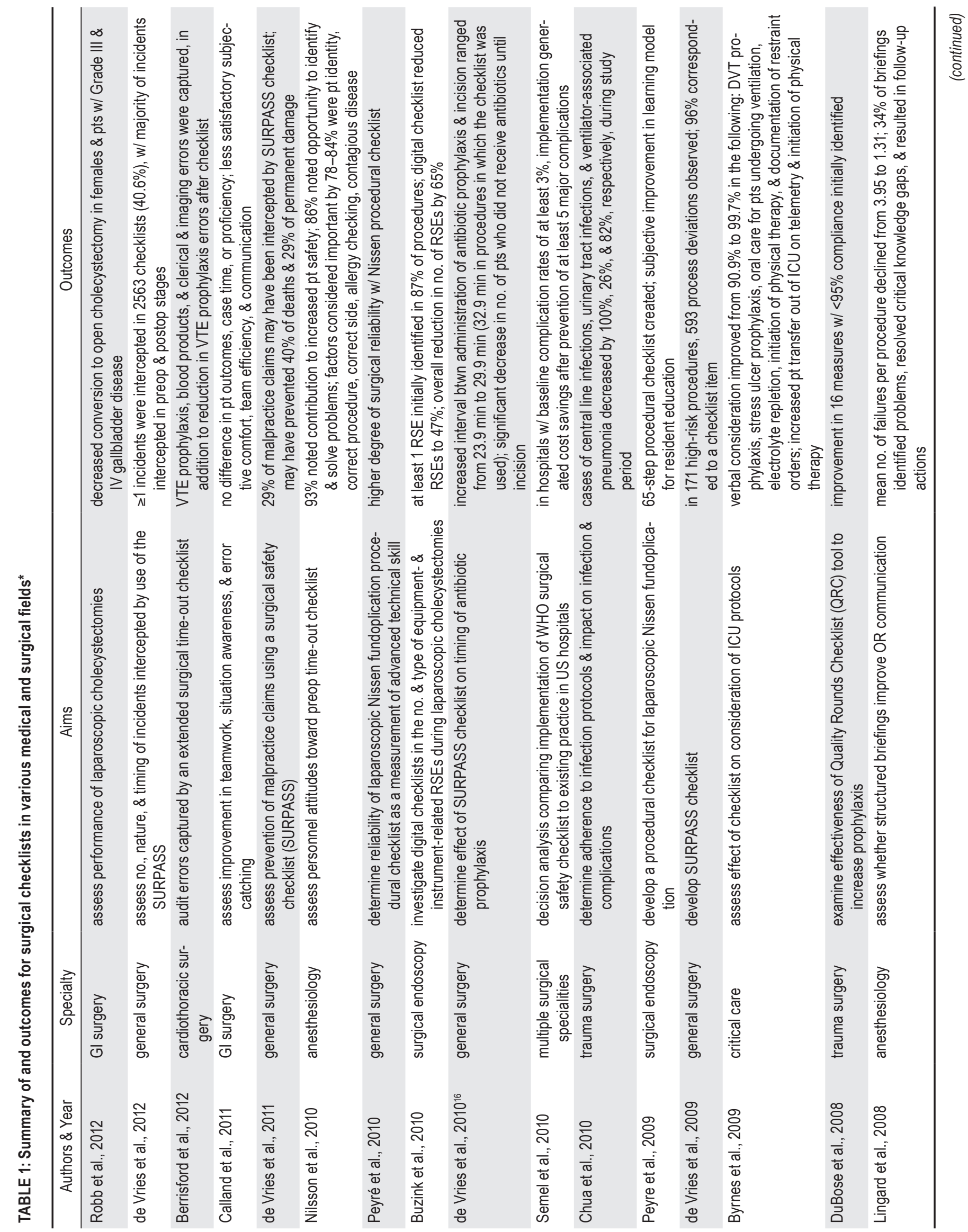




\section{S. L. Zuckerman et al.}

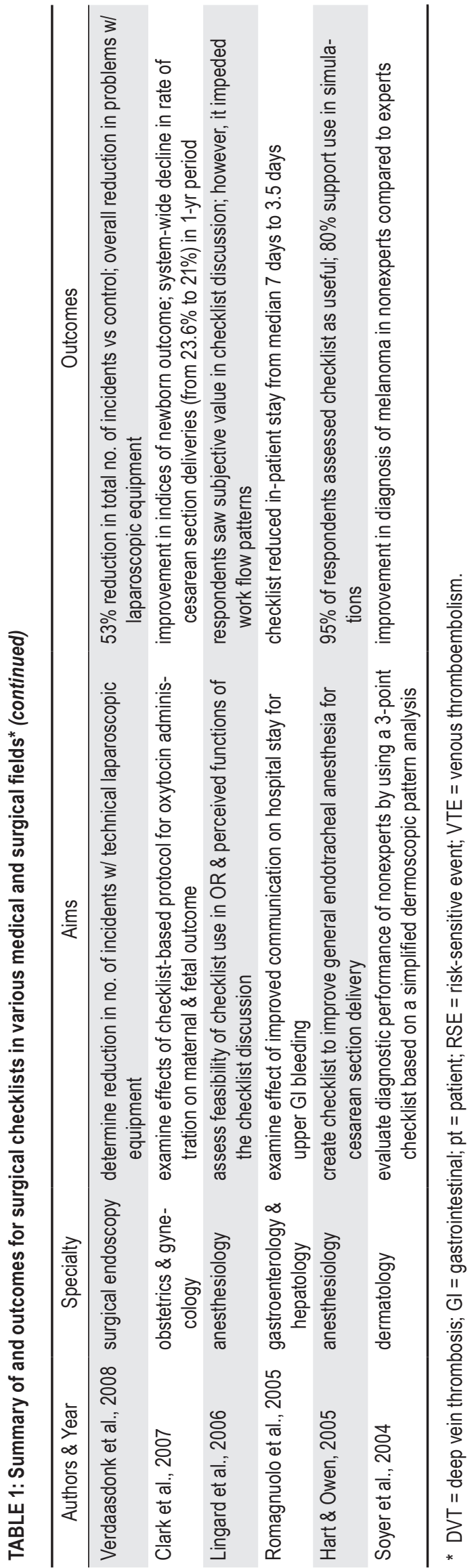

their results in 28 patients treated for either Parkinson disease or essential tremor. ${ }^{39}$ The first series of 17 patients underwent DBS without the use of a checklist, whereas the remaining 11 were treated following checklist implementation. In this relatively small study, the use of a checklist decreased the incidence of major errors more than 3-fold; from 11 to 3 . A similar trend was seen regarding minor errors, and among the 5 cases without a single detected error, each used the checklist protocol. Although small in scope, this investigation emphasizes the importance of a systematic and detailed means by which to identify and minimize preventable errors. Indeed, further studies are necessary to validate this tool, but in the meantime Kramer and coauthors have provided a benchmark for the functional neurosurgeon. We summarize their findings in Table 4.

Vascular Neurosurgery. This type of neurosurgery has perhaps the greatest potential for preventing devastating complications. Often involving critically ill patients in emergency situations, whether the procedure involves an endovascular technique or open microsurgery, checklists can vastly improve safety in this high-risk patient population.

With respect to endovascular procedures, Lawson et al. ${ }^{41}$ found that the most common complication involved the vascular access site (5\%), a relatively benign complication. Dawkins et al. ${ }^{15}$ found the following rates of complications in 2924 diagnostic angiograms: $0.41 \%$ significant puncture-site hematomas, $0.34 \%$ transient neurological events, and 1 nonfatal reaction to contrast agent. There were no permanent neurological complications. However, endovascular interventions for treatment, such as coil placement or stent insertion, pose much greater risks, including aneurysm rupture, arterial dissection, hemorrhage, thromboembolism, and microembolism. ${ }^{41}$ Vascular surgeries requiring craniotomy, such as aneurysm clipping, carry the most risk in this subspecialty. Bulters et al. ${ }^{6}$ analyzed 200 patients who underwent surgical clipping and found a 19\% complication rate, including direct brain injury, cranial nerve injury, postoperative hematoma, and ischemic events.

The current literature contains 2 types of vascular checklists: 1) a routine checklist for all cases, and 2) a checklist in case of emergency. Fargen et al. ${ }^{27}$ proposed an endovascular checklist to be completed prior to all endovascular interventions, as summarized in Table $5 .^{27}$ Conversely, in emergency situations, Taussky et al. ${ }^{57}$ postulated a checklist in case of aneurysm perforation during coil placement, seen in Table 6. Similarly, Chen ${ }^{10}$ formed 2 checklists in the following cases: 1) aneurysm rupture, with overall goals of hemostasis and ICP management; and 2) thromboembolic events, with overall goals of thrombolysis and distal perfusion optimization, as summarized in Table 7. Interestingly, Chen divided his checklists into individual OR personnel roles, rather than team responsibilities, suggesting an alternate manner to delegate responsibility.

Spine Surgery. Rates of spine surgery have increased steadily in recent years, and the US currently has the highest rate of spine surgery in the world. ${ }^{22,23}$ As the use 
Neurosurgical checklists: literature review

TABLE 2: Summary of and outcomes for validated neurosurgery operative checklists*

\begin{tabular}{|c|c|c|c|}
\hline Authors \& Year & Specialty & Aims & Outcomes \\
\hline Fargen et al., 2012 & vascular & $\begin{array}{l}\text { standardize unique demands of neurointerven- } \\
\text { tional procedures }\end{array}$ & $\begin{array}{l}\text { after checklist implementation, total no. of ad- } \\
\text { verse events was reduced by } 35 \%, \& 95 \% \text { of } \\
\text { staff championed checklist continuation }\end{array}$ \\
\hline Kramer et al., 2012 & $\begin{array}{l}\text { stereotactic \& functional } \\
\text { neurosurgery }\end{array}$ & $\begin{array}{l}\text { assess improvement in no. of errors w/ long-term } \\
\text { checklist use }\end{array}$ & $\begin{array}{l}\text { reduction in no. of errors after } 1 \mathrm{yr} \text { of use, from } \\
3.2 \text { to } 0.8 \text { total errors per case }\end{array}$ \\
\hline $\begin{array}{l}\text { Da Silva-Freitas et al., } \\
\quad 2012\end{array}$ & general neurosurgery & $\begin{array}{l}\text { evaluate a modified WHO surgical safety check- } \\
\text { list on the safety \& quality of care of neurosur- } \\
\text { gical pts }\end{array}$ & $\begin{array}{l}\text { identification of } 51 \text { events in } 44 \text { ops; correction } \\
\text { of } 88 \% \text { of errors prior to initiation of surgery }\end{array}$ \\
\hline Matsumae et al., 2011 & general neurosurgery & $\begin{array}{l}\text { evaluate effect on surgical quality \& communica- } \\
\text { tion }\end{array}$ & NA \\
\hline Chen, 2011 & vascular & $\begin{array}{l}\text { design endovascular checklists in the event of an- } \\
\text { eurysm perforation \& thromboembolic event }\end{array}$ & NA \\
\hline Lyons, 2010 & general neurosurgery & $\begin{array}{l}\text { prevent rare errors, ensure correct imaging stud- } \\
\text { ies, \& ensure antibiotic prophylaxis }\end{array}$ & $\begin{array}{l}\text { no wrong-site, wrong-procedure, or wrong- } \\
\text { patient error in } 8 \text { yrs of study; initiation of } \\
\text { safety culture }\end{array}$ \\
\hline Taussky et al., 2010 & vascular & $\begin{array}{l}\text { design endovascular checklist in event of aneu- } \\
\text { rysm perforation during coil insertion }\end{array}$ & NA \\
\hline Connolly et al., 2009 & $\begin{array}{l}\text { stereotactic \& functional } \\
\text { neurosurgery }\end{array}$ & detect \& remediate procedural errors & $\begin{array}{l}\text { no change in no. of errors; decreased time to } \\
\text { complete checklist }\end{array}$ \\
\hline NASS, 2001 & spine & prevent wrong-site, wrong-level surgery & NA \\
\hline
\end{tabular}

* NA = not assessed.

of spine surgery and instrumented fusion increases, so do complication rates. Potential complications encountered during spine surgery are vast, and can occur during the intraoperative and postoperative period. This morbidity includes durotomy, pseudomeningocele, transient neurological deficit, and permanent neurological deficit, in addition to long-term complications such as pseudarthroses, adjacent-segment disease, and hardware failure. However, one of the most preventable complications in spine surgery is wrong-level surgery. ${ }^{21}$ Wrong-level surgery is defined as a surgical procedure performed at the correct site but at the wrong level of the operative field; for example, performing a laminectomy on an unintended intervertebral level adjacent to an intervertebral level with an identified pathological entity. Ammerman et al. ${ }^{2}$ reported that without intraoperative radiographs, surgeons initially exposed the wrong level $15 \%$ of the time in a

\section{TABLE 3: General neurosurgical operative site checklist developed by Lyons}

Physician:
Procedure:
Date:
$\square \quad$ Confirmed identity of the patient
$\square \quad$ Confirmed medical record is for the correct patient
$\square \quad$ Confirmed x-rays are for the correct patient
$\square \quad$ Confirmed the correct op
$\square \quad$ Confirmed that consent form is signed for the correct op
$\square \quad$ Antibiotic given as ordered
Signature of surgeon completing the checklist:

Neurosurg Focus / Volume 33 / November 2012 prospective study of 100 discectomies. A 2010 study stated that wrong-level surgery at the L5-S1 region was the most common, with wrong-level surgery occurring in an average of 6.8 discectomies for every 10,000 procedures performed. ${ }^{21}$

In 2001, the NASS developed the "Sign, Mark and Xray" program. This program consists of a checklist seeking to improve patient safety and decrease complications during spine operations, as seen in Table $8 .{ }^{47}$ However, evidence suggests that the NASS checklist is insufficient to minimize wrong-level surgery. Later this was ratified into the "Universal Protocol for Preventing Wrong Site, Wrong Procedure, Wrong Person Injury," which has since been mandated for all accredited hospitals. ${ }^{36}$ The NASS checklist is more than a decade old, and to reduce wrong-level surgery, this checklist should be augmented with intraoperative imaging after exposure and marking of a fixed anatomical structure. ${ }^{21}$ Currently, spine surgery lacks a comprehensive perioperative checklist whose implementation has been able to demonstrate a reduction in wrong-level surgery.

Tumor and Pediatrics. Oncology and pediatric neurosurgery represent 2 of the most understudied areas in the checklist literature. Tumor surgery, especially lesions involving the skull base, presents a challenge to even the most experienced surgeons. Recent reports have shown complication rates of skull base surgery to be as high as $48.6 \% .{ }^{24}$ In a study of 30 patients undergoing skull base tumor resection, Sakashita et al. ${ }^{52}$ identified a complication in $40 \%$ of cases, and found that those with prior chemotherapy or radiation and dural resection had higher complication rates. No checklist aiming to prevent errors 
TABLE 4: Functional neurosurgery OR checklist developed by Kramer et al.*

\begin{tabular}{|c|c|}
\hline \multicolumn{2}{|c|}{ I. Frame placement } \\
\hline$\square$ & Complete pin set \\
\hline$\square$ & Frame bolts tight \\
\hline$\square$ & Localizer purged \\
\hline & Nose \& occiput clear \\
\hline & Head inspected for previous lead, shunt, or craniotomy \\
\hline & Local anesthetic injected \\
\hline \multicolumn{2}{|c|}{ OK to place pins } \\
\hline & Pins tight \\
\hline & Frame center rechecked \\
\hline & Frame tools \& local anesthetic on cart OK to travel \\
\hline \multicolumn{2}{|c|}{ OK to travel } \\
\hline \multicolumn{2}{|r|}{ II. Targeting \& positioning } \\
\hline \multicolumn{2}{|c|}{ MRI } \\
\hline & Frame $x$-translation $<3 \mathrm{~mm}$; actual value \\
\hline & Roll, yaw, pitch acceptable \\
\hline \multicolumn{2}{|c|}{ OR } \\
\hline & Lt target systematic error $=x+1.5$ \\
\hline & Rt target systematic error $=x-1$ \\
\hline & Mayfield adaptor \& headrest tight \\
\hline & Pin sites reinjected \\
\hline \multicolumn{2}{|c|}{ OK to scrub } \\
\hline \multicolumn{2}{|c|}{ III. Incision \& bur hole } \\
\hline$\square$ & Fluoroscopy time to center $=$ \\
\hline & Inject local anesthetic \\
\hline & Recheck coordinates \& verify transcription to field \\
\hline & Bur location "makes sense" \\
\hline & Reminder to change $x$ for contralat (check when called) \\
\hline & Reverify side if unilat \\
\hline & x-relaxation \\
\hline \multicolumn{2}{|c|}{ OK to start } \\
\hline & Cannula true \\
\hline & z-offset 25 \\
\hline & Microelectrode correct length \\
\hline \multicolumn{2}{|r|}{ IV. Recording \& implantation } \\
\hline & Read declination \& azimuth \\
\hline & Run simulation \\
\hline & Zero motor \\
\hline & Setscrews tight \\
\hline & $\mathrm{SBP}<140 \mathrm{~mm} \mathrm{Hg}$ \\
\hline \multicolumn{2}{|c|}{ OK to cannulate } \\
\hline & Macroelectrode correct length \\
\hline & Electrode adapter attached \\
\hline \multicolumn{2}{|r|}{ OK to implant } \\
\hline & $\begin{array}{l}\text { For bilat case, change x-coordinate \& repeat sublist "R\&l" (check } \\
\text { when called) }\end{array}$ \\
\hline & Reverify generator implantation site(s) \\
\hline$\square$ & Sponge count correct \\
\hline
\end{tabular}

(continued)
TABLE 4: Functional neurosurgery OR checklist developed by Kramer et al.* (continued)

\begin{tabular}{l}
\hline OK to close \\
V. Part B before closing \\
$\square \quad$ Lead-to-extension setscrews tight \\
$\square \quad$ Lt boot white/rt boot clear \\
$\square \quad$ Identify It \& rt for generator \\
$\square \quad$ Skip incision closed \\
$\square \quad$ Check for buttonhole \\
OK to close
\end{tabular}

${ }^{*} \mathrm{R} \& \mathrm{I}=$ recording and implantation; $\mathrm{SBP}=$ systolic blood pressure.

specific to brain tumor resection or biopsy currently exists. However, Arriaga et al. ${ }^{3}$ created a clinical pathway for acoustic neuroma management, specifically mandating ICU bed days aimed at cutting costs. Additionally, Kraus et al. ${ }^{40}$ published a standardized regimen of antibiotics to prevent infectious complications after skull base surgery, and found a significant reduction when using a regimen consisting of ceftazidime, flagyl, and vancomycin. Neither project addressed intraoperative checklists. . $^{3,40}$

Complications in pediatric neurosurgery can cause significant morbidity and lead to repeat surgical intervention. Operating on newborns involves challenges unique to pediatrics. ${ }^{1}$ Drake et al..$^{25}$ evaluated 1082 pediatric neurosurgical procedures and noted a $16.4 \%$ complication rate, with the most common complications occurring in vascular surgery $(41.7 \%)$ and brain tumor surgery $(27.9 \%)$. The most common complications were CSF leakage, new neurological deficit, early shunt or endoscopic ventriculostomy obstruction, and shunt infection.

In a thorough review of the oncology and pediatric neurosurgical literature, no perioperative checklists were found. This represents an active area of research, in which standardized protocols are needed.

\section{Discussion}

The field of neurosurgery is at an exciting point with respect to quality improvement and surgical checklists. The majority of checklists have evolved in the last 4 years. If this trend continues, an exponential growth in operative checklists is expected, aimed at standardizing procedures and maximizing patient safety. After reviewing the literature, several themes arose.

The term "checklist" defines several different entities. First, there are general surgical checklists applicable to all procedures, aimed at confirming the most vital identifying information-correct patient, procedure, and surgical site..$^{15,44-46}$ These measures target the most salient aspects of any surgical case without standardizing specifics of an operation. Nearly all surgical subspecialties, including neurosurgery, gained experience with generic checklists after the Joint Commission mandated a standardized time-out. Second, there are checklists aimed at the successful completion of a specific type of operation. ${ }^{30,39}$ Third, in the case of unexpected intraoperative emergencies, checklists exist to standardize the un- 
Neurosurgical checklists: literature review

TABLE 5: Endovascular neurosurgery safety checklist developed by Fargen et al.

\begin{tabular}{|c|}
\hline I. Before induction of anesthesia \\
\hline Patient has confirmed: \\
\hline$\square \quad$ Identity \\
\hline$\square$ Procedure \\
\hline$\square$ Consent \\
\hline$\square \quad \square \quad$ Does the patient need an arterial line or anesthesia? \\
\hline Yes No \\
\hline$\square \quad \square \quad$ Known allergy to contrast or anesthetic? \\
\hline Yes No \\
\hline$\square \quad \square \quad$ Difficult airway/aspiration risk? \\
\hline Yes No \\
\hline$\square \quad \square \quad$ Patient radiation level/planned radiation exposure discussed \\
\hline Yes No \\
\hline$\square \quad \square \quad$ Any chance patient may be pregnant? (Perform pregnancy test if yes) \\
\hline Yes No \\
\hline Radiation technologist confirms correct patient information logged in computer \\
\hline II. Before obtaining access \\
\hline$\square \quad$ Confirm that all team members have introduced themselves by name \& role \\
\hline$\square \quad$ Proceduralist \& anesthesia team member confirm patient \& procedure \\
\hline Proceduralist confirms: \\
\hline$\square \quad$ Sheath size \\
\hline$\square \quad$ Initial catheter \& wire \\
\hline$\square \quad$ No. of pressure bags \\
\hline$\square \quad$ Planned instruments \& procedure \\
\hline$\square$ Access/tortuosity concerns \\
\hline$\square \quad$ Pulses in ankle/wrist palpated \& results documented \\
\hline Patient wt $\_$kg \\
\hline Maximum contrast dose (for given $\mathrm{wt}$ ): ___ $\mathrm{ml}$ \\
\hline $\begin{array}{l}\square \\
\text { Yes No }\end{array}$ \\
\hline$\square \quad \square \quad$ Heparin needed? If yes, starting dose: ___ units \\
\hline Yes No \\
\hline$\square \quad \square \quad$ Is patient on blood thinners? If yes, \\
\hline III. Before patient leaves interventional radiology suite \\
\hline P Proceduralist confirms arteriotomy closure \\
\hline$\square$ Team confirms amount of contrast given: ___ $\mathrm{ml}$ \\
\hline$\square \quad$ Proceduralist confirms pulses in ankle/wrist palpated \& results documented \\
\hline$\square \quad \square \quad$ Any equipment problems that need to be addressed? \\
\hline Yes No \\
\hline$\square \quad$ Team confirms who will discuss procedural results w/ primary team \& patient \&/or family \\
\hline
\end{tabular}

planned..$^{10,64}$ All 3 brands of checklists fill a niche within neurosurgery.

Checklist organization also varies. Whereas Taussky et al. identified general team duties in case of aneurysm rupture, Chen et al. divided team responsibilities into individual roles-proceduralist, anesthesia, nursing, and technician. No data exist as to which model is more efficacious. Similarly, Lyons et al. published the only checklist that required a direct surgeon signature. Most checklist measures are implemented by nursing staff or by anyone on the operative team.
But is the mechanistic approach of simply completing a checklist enough? Creating a culture of safety and recognizing hierarchical communication constraints are paramount to successful checklist implementation. The field of aviation is replete with research on communication in high-pressure situations. The work of Sexton and Helmreich ${ }^{54}$ on cockpit linguistics showed that the way in which crew members verbally interact with one another impacted performance and error rates. Increased words and use of the first person plural (we, our, us) were linked to increased performance and communication, and de- 


\section{S. L. Zuckerman et al.}

TABLE 6: Vascular complications in neurosurgery Checklist 1 developed by Taussky et al.*

Aneurysm perforation checklist
Identification of perforation
$\square \quad$ Wire/coil beyond aneurysm edge
$\square \quad$ Alert anesthesia about perforation
$\square \quad$ Do not retract wire/catheter/coil
$\square \quad$ Perform angiography to look for extravasation
$\square \quad$ Look at transit time
$\square \quad$ Consider CT now/after
Clinical examination
$\square \quad$ Pupil status
$\square \quad$ Glasgow Coma Scale score
$\square \quad$ BP change
$\square \quad$ Focal neurological deficit
$\square \quad$ Agitation
Medical management
$\square \quad$ BP modulation
$\square \quad$ Administer protamine if patient is on anticoagulation therapy
$\square \quad$ Consider mannitol
$\square \quad$ Consider pentobarbital
Endovascular management
$\square \quad$ Consider second microcatheter
$\square \quad$ Consider balloon inflation
$\square \quad$ Continue w/ packing of aneurysm
Closing up
$\square \quad$ Inform ICU
$\square \quad$ Inform neurosurgery
$\square \quad$ Consider EVD/craniotomy

* $\mathrm{BP}=$ blood pressure; $\mathrm{EVD}=$ external ventricular drain.

creased error rates. Additionally, the language used in the preceding flight impacted subsequent flights. Helmreich and Musson ${ }^{34}$ also defined the following behaviors as ones that help prevent error and support teamwork: monitoring and challenging other team members, defining leadership responsibilities, sharing mental models, and briefing and debriefing.

In another paper examining the effects of crew resource management, Helmreich ${ }^{33}$ observed that the greatest value of communication is in discovering hidden threats that can lead to error. Thomas et al. ${ }^{58}$ polled ICU physicians and nurses and asked them to rate collaboration and communication with each other. Physicians rated $73 \%$ of nurses favorably and $70 \%$ of physicians favorably, whereas nurses rated $71 \%$ of nurses favorably, but only $33 \%$ of physicians favorably. From the nursing perspective, much improvement in communication and teamwork was needed between nurses and doctors. In the OR, researchers have studied communication and have defined the interface between surgeon and anesthesiologist as one of client and service provider, rather than as a cohesive team. ${ }^{33,34}$ The more appropriate conceptualization of an OR is of a single team in which the surgeon is not the captain, and all team members-anesthesiologist, sur-
TABLE 7: Vascular complications in neurosurgery Checklist 2 developed by Chen*

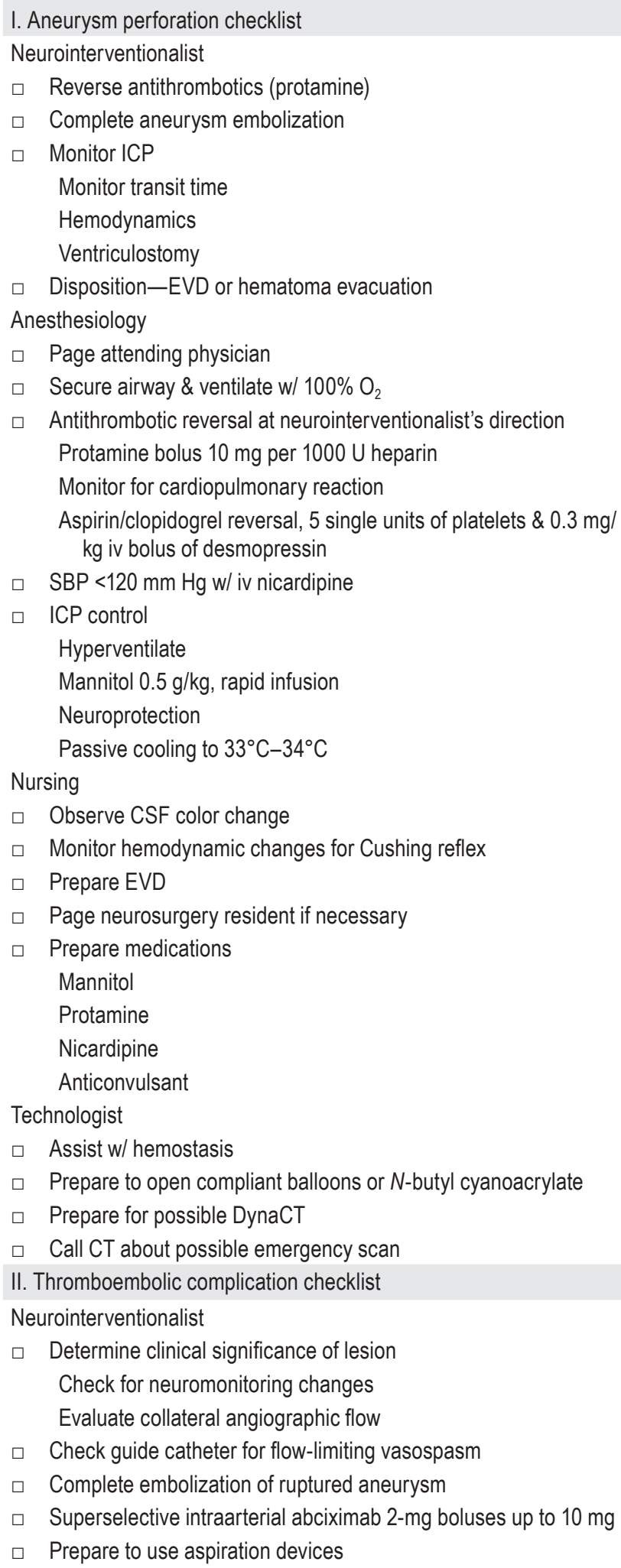

(continued) 


\section{TABLE 7: Vascular complications in neurosurgery Checklist 2 developed by Chen* (continued)}

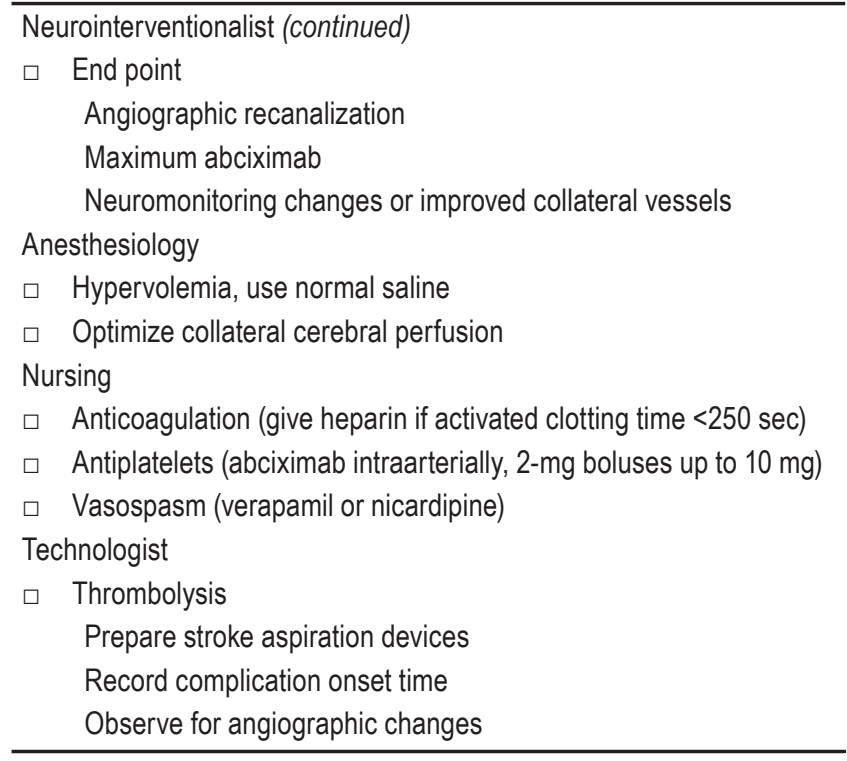

* iv $=$ intravenous.

geon, nurses, support staff-feel empowered to speak if a safety issue arises. ${ }^{33}$ Overall, successful checklist implementation is more than checking boxes. A culture of open communication and an egalitarian relationship between all surgical team members are required. Under this model, hierarchical rivalries become subordinate to achieving patient safety as the highest end point.

\section{Conclusions}

The neurosurgical literature on checklists is limited, yet currently evolving. By reviewing current neurosurgical peer-reviewed checklists, it is our aim to educate our colleagues on how leaders in this area have standardized patient safety measures, with the end goal being the de- sign of successful quality measures to improve patient safety.

\section{Disclosure}

Dr. Mocco is a consultant for the following companies: Lazarus Effect, Inc.; NFocus; and Edge Therapeutics. He has direct stock ownership in Blockade Therapeutics.

Author contributions to the study and manuscript preparation include the following. Conception and design: Mocco. Drafting the article: Zuckerman, Green, Carr, Dewan, Morone. Critically revising the article: Mocco, Zuckerman, Carr, Dewan, Morone. Reviewed submitted version of manuscript: Mocco, Zuckerman, Green. Approved the final version of the manuscript on behalf of all authors: Mocco. Study supervision: Mocco.

\section{References}

1. Adzick NS, Thom EA, Spong CY, Brock JW III, Burrows PK, Johnson MP, et al: A randomized trial of prenatal versus postnatal repair of myelomeningocele. N Engl J Med 364:9931004,2011

2. Ammerman JM, Ammerman MD, Dambrosia J, Ammerman BJ: A prospective evaluation of the role for intraoperative $\mathrm{x}$ ray in lumbar discectomy. Predictors of incorrect level exposure. Surg Neurol 66:470-474, 2006

3. Arriaga MA, Gorum M, Kennedy A: Clinical pathways in acoustic tumor management. Laryngoscope 107:602-606, 1997

4. Berrisford RG, Wilson IH, Davidge M, Sanders D: Surgical time out checklist with debriefing and multidisciplinary feedback improves venous thromboembolism prophylaxis in thoracic surgery: a prospective audit. Eur J Cardiothorac Surg 41:1326-1329, 2012

5. Brennan TA, Leape LL, Laird NM, Hebert L, Localio AR, Lawthers AG, et al: Incidence of adverse events and negligence in hospitalized patients. Results of the Harvard Medical Practice Study I. N Engl J Med 324:370-376, 1991

6. Bulters DO, Santarius T, Chia HL, Parker RA, Trivedi R, Kirkpatrick PJ, et al: Causes of neurological deficits following clipping of 200 consecutive ruptured aneurysms in patients with good-grade aneurysmal subarachnoid haemorrhage. Acta Neurochir (Wien) 153:295-303, 2011

7. Buzink SN, van Lier L, de Hingh IH, Jakimowicz JJ: Risksensitive events during laparoscopic cholecystectomy: the influence of the integrated operating room and a preoperative checklist tool. Surg Endosc 24:1990-1995, 2010

\section{TABLE 8: Spine surgery wrong-level checklist developed by NASS*}

口 Involve patient in confirming the operative site either through informed consent or during the actual marking. Surgeons are encouraged to obtain informed consent personally. Copies of the operative permit/informed consent form should state the site \& side of surgery \& be shared w/ patient, surgeon, anesthesiologist, assistant or scrub nurse, \& circulating nurse.

$\square \quad$ Sign your name to the operative site.

$\square \quad$ Each member of the operative team should verify the correct site.

- Verify that x-rays \& medical records are for the correct patient, as well as confirming identity of the patient.

Each of the following items should be double-checked against the marked site:

口 Medical records

口 $\quad$-rays \& other imaging studies (marked "L" or "R" to prevent being placed backward on the light box)

- Informed consent

- OR/anesthesia record

- Consider having your assistant or scrub nurse always stand opposite the side where the surgeon should stand.

- Consider or suggest an intraoperative $x$-ray during surgery, after exposure using markers that do not move to confirm the vertebral level to be operated. Consider a radiology reading.

\footnotetext{
* The "Sign, Mark \& X-ray (SMaX)" checklist; see reference 46.
} 


\section{S. L. Zuckerman et al.}

8. Byrnes MC, Schuerer DJ, Schallom ME, Sona CS, Mazuski JE, Taylor BE, et al: Implementation of a mandatory checklist of protocols and objectives improves compliance with a wide range of evidence-based intensive care unit practices. Crit Care Med 37:2775-2781, 2009

9. Calland JF, Turrentine FE, Guerlain S, Bovbjerg V, Poole GR, Lebeau K, et al: The surgical safety checklist: lessons learned during implementation. Am Surg 77:1131-1137, 2011

10. Chen M: A checklist for cerebral aneurysm embolization complications. J Neurointerv Surg [epub ahead of print], 2011

11. Chua C, Wisniewski T, Ramos A, Schlepp M, Fildes JJ, Kuhls DA: Multidisciplinary trauma intensive care unit checklist: impact on infection rates. J Trauma Nurs 17:163-166, 2010

12. Clark S, Belfort M, Saade G, Hankins G, Miller D, Frye D, et al: Implementation of a conservative checklist-based protocol for oxytocin administration: maternal and newborn outcomes. Am J Obstet Gynecol 197:480.e1-480.e5, 2007

13. Connolly PJ, Kilpatrick M, Jaggi JL, Church E, Baltuch GH: Feasibility of an operational standardized checklist for movement disorder surgery. A pilot study. Stereotact Funct Neurosurg 87:94-100, 2009

14. Da Silva-Freitas R, Martín-Laez R, Madrazo-Leal CB, Villena-Martin M, Valduvieco-Juaristi I, Martínez-Agüeros JA, et al: [Establishment of a modified surgical safety checklist for the neurosurgical patient: Initial experience in 400 cases.] Neurocirugia (Astur) 23:60-69, 2012 (Span)

15. Dawkins AA, Evans AL, Wattam J, Romanowski CA, Connolly DJ, Hodgson TJ, et al: Complications of cerebral angiography: a prospective analysis of 2,924 consecutive procedures. Neuroradiology 49:753-759, 2007

16. de Vries EN, Dijkstra L, Smorenburg SM, Meijer RP, Boermeester MA: The SURgical PAtient Safety System (SURPASS) checklist optimizes timing of antibiotic prophylaxis. Patient Saf Surg 4:6, 2010

17. de Vries EN, Eikens-Jansen MP, Hamersma AM, Smorenburg SM, Gouma DJ, Boermeester MA: Prevention of surgical malpractice claims by use of a surgical safety checklist. Ann Surg 253:624-628, 2011

18. de Vries EN, Hollmann MW, Smorenburg SM, Gouma DJ, Boermeester MA: Development and validation of the SURgical PAtient Safety System (SURPASS) checklist. Qual Saf Health Care 18:121-126, 2009

19. de Vries EN, Prins HA, Bennink MC, Neijenhuis P, van Stijn I, van Helden SH, et al: Nature and timing of incidents intercepted by the SURPASS checklist in surgical patients. BMJ Qual Saf 21:503-508, 2012

20. de Vries EN, Prins HA, Crolla RM, den Outer AJ, van Andel G, van Helden SH, et al: Effect of a comprehensive surgical safety system on patient outcomes. N Engl J Med 363:19281937, 2010

21. Devine J, Chutkan N, Norvell DC, Dettori JR: Avoiding wrong site surgery: a systematic review. Spine (Phila Pa 1976) 35 (9 Suppl):S28-S36, 2010

22. Deyo RA, Gray DT, Kreuter W, Mirza S, Martin BI: United States trends in lumbar fusion surgery for degenerative conditions. Spine (Phila Pa 1976) 30:1441-1447, 2005

23. Deyo RA, Mirza SK: Trends and variations in the use of spine surgery. Clin Orthop Relat Res 443:139-146, 2006

24. Dias FL, Sá GM, Kligerman J, Lopes HF, Wance JR, Paiva FP, et al: Complications of anterior craniofacial resection. Head Neck 21:12-20, 1999

25. Drake JM, Riva-Cambrin J, Jea A, Auguste K, Tamber M, Lamberti-Pasculli M: Prospective surveillance of complications in a pediatric neurosurgery unit. Clinical article. J Neurosurg Pediatr 5:544-548, 2010

26. DuBose JJ, Inaba K, Shiflett A, Trankiem C, Teixeira PG, Sa$\lim$ A, et al: Measurable outcomes of quality improvement in the trauma intensive care unit: the impact of a daily quality rounding checklist. J Trauma 64:22-29, 2008
27. Fargen KM, Velat GJ, Lawson MF, Firment CS, Mocco J, Hoh BL: Enhanced staff communication and reduced near-miss errors with a neurointerventional procedural checklist. J Neurointerv Surg [epub ahead of print], 2012

28. Gawande A: Checklist Manifesto: How to Get Things Right. New York: Metropolitan Books, 2009

29. Gawande AA, Thomas EJ, Zinner MJ, Brennan TA: The incidence and nature of surgical adverse events in Colorado and Utah in 1992. Surgery 126:66-75, 1999

30. Halpern C, Hurtig H, Jaggi J, Grossman M, Won M, Baltuch G: Deep brain stimulation in neurologic disorders. Parkinsonism Relat Disord 13:1-16, 2007

31. Hart EM, Owen H: Errors and omissions in anesthesia: a pilot study using a pilot's checklist. Anesth Analg 101:246-250, 2005

32. Haynes AB, Weiser TG, Berry WR, Lipsitz SR, Breizat AH, Dellinger EP, et al: A surgical safety checklist to reduce morbidity and mortality in a global population. N Engl J Med 360:491-499, 2009

33. Helmreich RL: On error management: lessons from aviation. BMJ 320:781-785, 2000

34. Helmreich RL, Musson DM: Surgery as team endeavour. Can J Anaesth 47:391-392, 2000

35. Johnson WG, Brennan TA, Newhouse JP, Leape LL, Lawthers AG, Hiatt HH, et al: The economic consequences of medical injuries. Implications for a no-fault insurance plan. JAMA 267:2487-2492, 1992

36. Joint Commission: Facts about the Universal Protocol. (http://www.jointcommission.org/assets/1/18/Universal\%20 Protocol\%201\%204\%20111.PDF) [Accessed October 1, 2012]

37. Kern DS, Kumar R: Deep brain stimulation. Neurologist 13: 237-252, 2007

38. Kohn LT, Corrigan JM, Donaldson MS (eds): To Err Is Human: Building a Safer Health System. Washington, DC: National Academies Press, 2000

39. Kramer DR, Halpern CH, Connolly PJ, Jaggi JL, Baltuch GH: Error reduction with routine checklist use during deep brain stimulation surgery. Stereotact Funct Neurosurg 90:255259,2012

40. Kraus DH, Gonen M, Mener D, Brown AE, Bilsky MH, Shah JP: A standardized regimen of antibiotics prevents infectious complications in skull base surgery. Laryngoscope 115:1347-1357, 2005

41. Lawson MF, Velat GJ, Fargen KM, Mocco J, Hoh BL: Interventional neurovascular disease: avoidance and management of complications and review of the current literature. J Neurosurg Sci 55:233-242, 2011

42. Lingard L, Regehr G, Orser B, Reznick R, Baker GR, Doran $\mathrm{D}$, et al: Evaluation of a preoperative checklist and team briefing among surgeons, nurses, and anesthesiologists to reduce failures in communication. Arch Surg 143:12-18, 2008

43. Lingard L, Whyte S, Espin S, Baker GR, Orser B, Doran D: Towards safer interprofessional communication: constructing a model of "utility" from preoperative team briefings. J Interprof Care 20:471-483, 2006

44. Lyons MK: Eight-year experience with a neurosurgical checklist. Am J Med Qual 25:285-288, 2010

45. Matsumae M, Nakajima Y, Morikawa E, Nishiyama J, Atsumi $\mathrm{H}$, Tominaga J, et al: Improving patient safety in the intra-operative MRI suite using an on-duty safety nurse, safety manual and checklist. Acta Neurochir Suppl 109:219-222, 2011

46. Nilsson L, Lindberget O, Gupta A, Vegfors M: Implementing a pre-operative checklist to increase patient safety: a 1-year follow-up of personnel attitudes. Acta Anaesthesiol Scand 54:176-182, 2010

47. North American Spine Society: Sign, Mark \& X-ray (SMaX): Prevent Wrong-Site Surgery. (http://www.spine. org/Pages/PracticePolicy/ClinicalCare/SMAX/Default.aspx) [Accessed September 25, 2012] 
48. Peyré SE, Peyré CG, Hagen JA, Sullivan ME: Reliability of a procedural checklist as a high-stakes measurement of advanced technical skill. Am J Surg 199:110-114, 2010

49. Peyre SE, Peyre CG, Hagen JA, Sullivan ME, Lipham JC, Demeester SR, et al: Laparoscopic Nissen fundoplication assessment: task analysis as a model for the development of a procedural checklist. Surg Endosc 23:1227-1232, 2009

50. Robb WB, Falk GA, Larkin JO, Waldron R Jr, Waldron RP: A 10-step intraoperative surgical checklist (ISC) for laparoscopic cholecystectomy-can it really reduce conversion rates to open cholecystectomy? J Gastrointest Surg 16:1318-1323, 2012

51. Romagnuolo J, Flemons WW, Perkins L, Lutz L, Jamieson PC, Hiscock CA, et al: Post-endoscopy checklist reduces length of stay for non-variceal upper gastrointestinal bleeding. Int J Qual Health Care 17:249-254, 2005

52. Sakashita T, Oridate N, Homma A, Nakamaru Y, Suzuki F, Hatakeyama H, et al: Complications of skull base surgery: an analysis of 30 cases. Skull Base 19:127-132, 2009

53. Semel ME, Resch S, Haynes AB, Funk LM, Bader A, Berry WR, et al: Adopting a surgical safety checklist could save money and improve the quality of care in U.S. hospitals. Health Aff (Millwood) 29:1593-1599, 2010

54. Sexton JB, Helmreich RL: Analyzing cockpit communications: the links between language, performance, error, and workload. Hum Perf Extrem Environ 5:63-68, 2000

55. Shinde S, Carter JA: Wrong site neurosurgery-still a problem. Anaesthesia 64:1-2, 2009

56. Soyer HP, Argenziano G, Zalaudek I, Corona R, Sera F, Talamini R, et al: Three-point checklist of dermoscopy. A new screening method for early detection of melanoma. Dermatology 208:27-31, 2004

57. Taussky P, Lanzino G, Cloft H, Kallmes D: A checklist in the event of aneurysm perforation during coiling. AJNR Am J Neuroradiol 31:E59, 2010
58. Thomas EJ, Sexton JB, Helmreich RL: Discrepant attitudes about teamwork among critical care nurses and physicians. Crit Care Med 31:956-959, 2003

59. Thomas EJ, Studdert DM, Burstin HR, Orav EJ, Zeena T, Williams EJ, et al: Incidence and types of adverse events and negligent care in Utah and Colorado. Med Care 38:261-271, 2000

60. Thomas EJ, Studdert DM, Newhouse JP, Zbar BI, Howard $\mathrm{KM}$, Williams EJ, et al: Costs of medical injuries in Utah and Colorado. Inquiry 36:255-264, 1999

61. Thomas EJ, Studdert DM, Runciman WB, Webb RK, Sexton EJ, Wilson RM, et al: A comparison of iatrogenic injury studies in Australia and the USA. I: Context, methods, casemix, population, patient and hospital characteristics. Int J Qual Health Care 12:371-378, 2000

62. Trunet P, Le Gall JR, Lhoste F, Regnier B, Saillard Y, Carlet J, et al: The role of iatrogenic disease in admissions to intensive care. JAMA 244:2617-2620, 1980

63. Verdaasdonk EG, Stassen LP, Hoffmann WF, van der Elst M, Dankelman J: Can a structured checklist prevent problems with laparoscopic equipment? Surg Endosc 22:2238-2243, 2008

64. Wilson RM, Runciman WB, Gibberd RW, Harrison BT, Newby L, Hamilton JD: The Quality in Australian Health Care Study. Med J Aust 163:458-471, 1995

65. Yu H, Neimat JS: The treatment of movement disorders by deep brain stimulation. Neurotherapeutics 5:26-36, 2008

Manuscript submitted July 15, 2012.

Accepted September 24, 2012.

Please include this information when citing this paper: DOI: 10.3171/2012.9.FOCUS12257.

Address correspondence to: J Mocco, M.D., 1211 Medical Center Drive, Nashville, Tennessee 37232. email: j.mocco@vanderbilt.edu. 